\title{
(Research Article) \\ Voltage Improvement in Distribution System using Shunt FACTS Device
}

\author{
Naman B. Bhatt ${ }^{1 *}$, Shabbir S. Bohra ${ }^{2}$ \\ ${ }^{1 * 2}$ Department of Electrical Engineering, Sarvajanik College of Engineering \& Technology, Athwalines, Surat-395 001 (India)
}

\begin{abstract}
FACTS (Flexible AC Transmission Systems) and in particular SVC (Static VAR Compensator) and STATCOM (Static Synchronous Compensator) are shunt devices used to control reactive power flow in distribution system. They offer remedies to voltage dips and swells, mitigating harmonic distortion, and restoring balance between phases due to unbalanced load or on occurrence of severe faults These may be caused by for instance in distributed generation, during dynamic operations in heavy induction motor load or high speed rail traffic. The paper focuses on performance of D-STATCOM for various load conditions and voltage fluctuations taking place in distribution systems for reactive power compensation. A MATLAB/Simulink ${ }^{\circledR}$ based simulation study is presented under balanced, unbalanced load and fault condition to validate voltage improvement concept. Static and dynamic performance of a \pm 3 MVAr D-STATCOM on a $11 \mathrm{kV}$ distribution network is validated.
\end{abstract}

Keywords: FACTS (Flexible AC Transmission Systems), SVC (Static VAR Compensator), STATCOM (Static Synchronous Compensator), VSC (Voltage Source Converter), DG (Distributed generation), MATLAB/SIMULINK.

\section{Introduction}

Electric power distribution network has become more increasingly important and plays an essential role in power system planning. This type of power systems has a major function to serve distributed customer loads along a feeder line; therefore under competitive environment of electricity market service of electric energy transfer must not be interrupted and at the same time there must provide reliable, stable and high quality of electric power. Utilities are presently facing a major challenge of grid integrating an increasing number of renewable energy based distributed generators (DGs) while ensuring stability, voltage regulation, and power quality. Load requirement is very less during night compared to day. During night due to high wind speed, wind farms (WFs) produce more power which result in rise of feeder voltages above allowable limits, typically $\pm 5 \%$ [1].

Voltage magnitude is one of the major factors that determine the quality of power supply. Load at distribution level are usually subjected to frequent voltage sag due to switching of highly inductive load such as arc furnaces, large induction motor switching and voltage swell because of switching off heavily loaded line, unbalanced fault in transmission line \& capacitive load switching. These sag and swell in power

*Corresponding Author: e-mail: naman.bhatt@scet.ac.in, Tel-+91-9879489915,

ISSN 2320-7590

(C) 2021 Darshan Institute of Engg. \& Tech., All rights reserved industry are highly undesirable and must be compensated as these leads to mal-operation of relays, hence circuit breaker which result in complete shut down of process plant result a loss of production and quality [2].

To complete this challenge, it requires an additional device to be installed suitable location in the network. The DSTATCOM is a voltage source converter (VSC) based custom power technology which can perform as a reactive power source in power systems. The D-STATCOM can regulate magnitude of voltage at a particular AC bus, at the point where it is connected, via generating or absorbing reactive power from the system [3, 4]. Apart from these voltage variations, the D-STATCOM is capable to enhance steady-state performances such as power factor correction and harmonic reduction of a particular feeder portion.

\section{D-STATCOM}

STATCOM is a shunt connected reactive power compensation device, which is capable to generate or absorb reactive power. The basic electronic block of STATCOM is VSC that converts an input dc voltage into three phase output voltage at fundamental frequency. It consists coupling transformer, a voltage source inverter and dc links capacitor. A capacitor is used to maintain constant de voltage to the inverter. The steady state power exchange between the device and the ac system is mainly reactive. The function of a VSC is a fully controllable voltage source matching the system 
voltage in phase and frequency, and with amplitude which can be continuously and rapidly controlled, so as to be used as the tool for reactive power control [5]. The amplitude of the STATCOM output voltage controls the reactive power exchange of the STATCOM with the ac system.
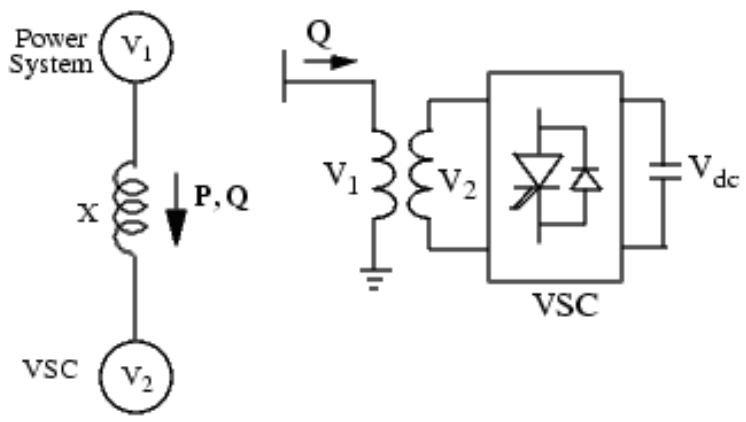

Figure 1. Operating Principle of the STATCOM

In the system, the VSC is connected to the system bus via a small reactor. With the VSC voltage and the bus voltage denoted $V_{2}$ and $V_{1}$ respectively, it can be shown that the output of the VSC can be expressed as follows:

$$
\begin{gathered}
P=\frac{V_{1} V_{2}}{X} \sin \delta \\
Q=\frac{V_{1} V_{2}}{X} \cos \delta-\frac{V_{1}^{2}}{X}
\end{gathered}
$$

$Q$ : Reactive power of the VSC

$V_{l}$ : Bus voltage

$V_{2}$ : Output voltage of converter

$\delta$ : Phase difference between the voltages

$X$ : Reactance of the coupling reactor

From equations (1) and (2) it can be seen that by choosing zero phase-shift between the bus voltage and the VSC voltage $(\delta=0)$, the VSC will act as a purely reactive element. (In reality, a small phase shift is allowed, in order to make up for the VSC losses.) It is further seen that if $V_{2}>V_{1}$, the VSC will supply reactive power acting as a capacitive load, on the other hand, if $V_{2}<V_{l}$, the VSC will act as an absorber of reactive power, acts as a inductive load [6].

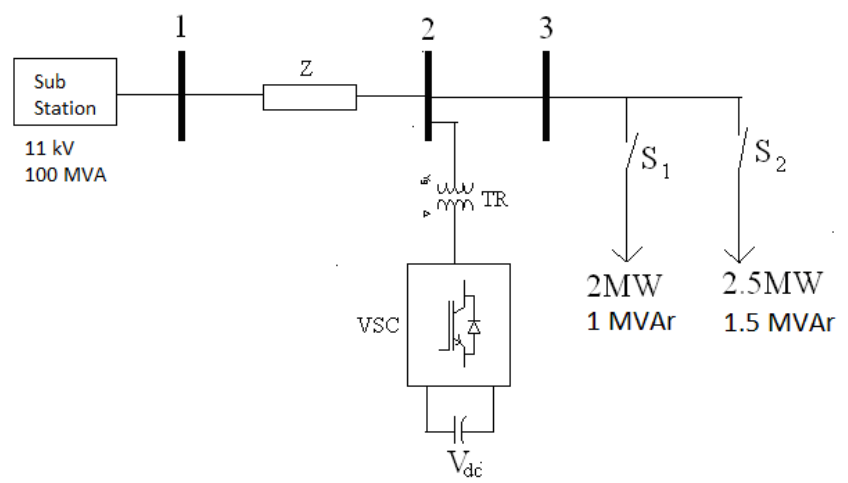

Figure 2. Simplified single line diagram of D-STATCOM connected to distribution network.

\section{D-STATCOM MODELING}

The STATCOM consists mainly of a PWM inverter connected to the network through a transformer. The DC link voltage is provided by capacitor $\mathrm{C}$ which is charged from power drawn from supply. The control system ensures the regulation of the bus voltage and the DC link voltage [7].

The reactive power transfer is controlled through the leakage reactance of the coupling transformer by using a secondary voltage in phase with the primary voltage on bus. In steady state, due to inverter losses the bus voltage always leads the inverter voltage by a small angle to supply a small active power.

The short circuit power at the $11 \mathrm{kV} \mathrm{B}$ bus is $100 \mathrm{MVA}$. The \pm 3 MVAr D-STATCOM is connected to the $11 \mathrm{kV}$ bus $\mathrm{B}_{2}$ through a $11 \mathrm{kV} / 0.440 \mathrm{kV}$ Wye/Delta transformer $[8,9]$. The secondary voltage is synthesized by a PWM inverter using a $3 \mathrm{kHz}$ chopping frequency. In order to minimize harmonic frequencies generated by the PWM, the output voltage of the inverter is filtered before being sent to the secondary of the transformer. The PWM pulse generator issues firing pulses to the IGBT inverter.

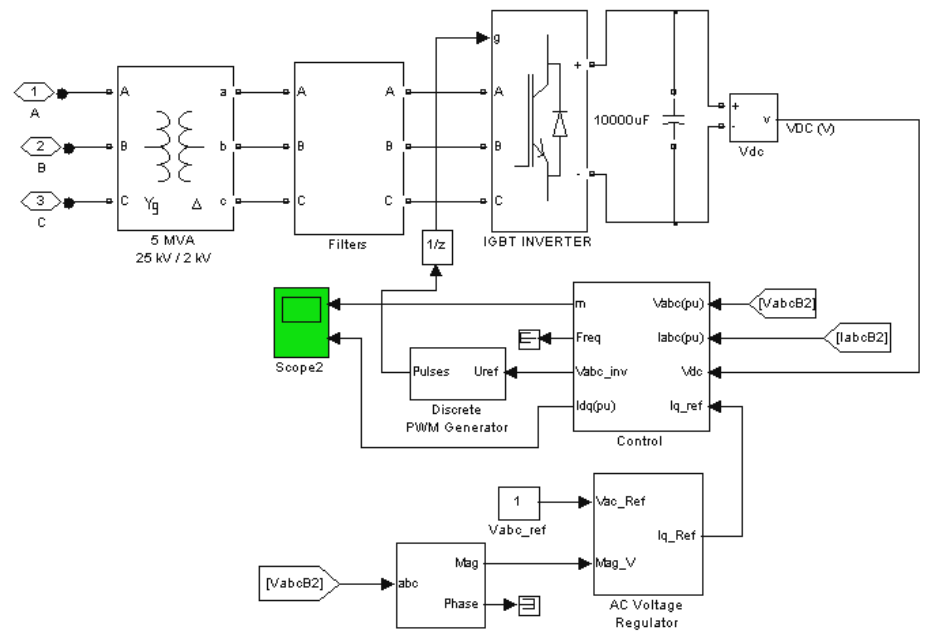

Figure 3. D-STATCOM on a $11 \mathrm{kV}$ Distribution Network

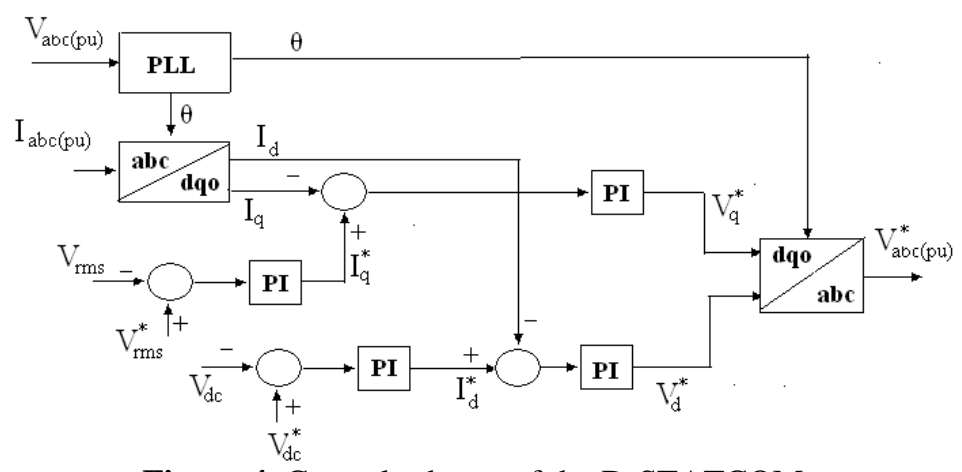

Figure 4. Control scheme of the D-STATCOM 
The three voltages at the STATCOM terminals are sent to a PLL which synchronizes on the zero crossing of the fundamental component of the phase $A$ voltage [10]. The $I_{d} \&$ $I_{q}$ currents are regulated by their respective PI regulators. The output of the $I_{q}$ regulator is the desired $V_{q}{ }^{*}$ voltage to be generated by the inverter. The $I_{d}$ current correspond to the small active power following into the STATCOM. The regulator follows a reference imposed by the DC bus voltage regulator. The output of the $I_{d}$ regulator is the desired $V_{d}{ }^{*}$ voltage to be generated by the inverter $[11,12]$.

\section{SIMULATION RESULTS}

The simulation study is carried out for different cases like voltage sag due to heavy load, unbalanced and fault condition. The simulation carried out for three different conditions as mentioned below to observe.

A. Simulation results of Voltage Sag due to heavy load

B. Simulation results of Unbalanced load

C. Simulation results of Unbalance Voltage Sag due to double line to ground fault with fault resistance of $120 \Omega$

During $0-0.4$ second, a load of $2 \mathrm{MW}+\mathrm{j} 1 \mathrm{MVAr}$ is connected resulting into load voltage of $0.9525 \mathrm{pu}$ without DSTATCOM as shown in figure 5. (a). With D-STATCOM connected, this load voltage is also improved to $1 \mathrm{pu}$ as shown in figure 5. (b).

During 0.4 - 0.6 second, a voltage sag is created by connecting an heavy RL load (i.e. $2.5 \mathrm{MW}+\mathrm{j} 1.5 \mathrm{MVAr}$ ). It is seen from the result that bus voltage $\mathrm{B}_{2}$ drops to $0.8915 \mathrm{pu}$ from 1 pu without D-STATCOM as shown in figure 5. (a). In contrast to that, when D-STATCOM is connected at the load point to improve the deviation in load voltage, a load voltage is seen to be maintained at almost 1 pu as shown in figure 5 . (b). The instantaneous voltage \& current waveform of phase $A$ at bus 2 are shown in figure 6. (a) \& figure 6. (b). The active $(\mathrm{P})$ \& reactive $(\mathrm{Q})$ power draw by load at bus 2 without D-STATCOM as shown in figure 7. (a). D-STATCOM injects reactive power at bus 2 during heavy load condition to maintain bus 2 voltage at 1 pu as shown in figure 7. (b).

Unbalanced voltage sag/swell is developed by connecting resistive load of $1 \mathrm{MW}$ to A-Phase, inductive load of $2 \mathrm{MW}+$ j1 MVAr to B-Phase \& capacitive load of $1.5 \mathrm{MW}$ - j1.5 MVAr to C-Phase. The instantaneous voltage waveforms of all three phases during unbalanced load condition are shown in figure 8. (a) without D-STATCOM \& figure 8. (b) with DSTATCOM. Hence, the voltage at load point $1.0081 \mathrm{pu}$, $0.9189 \mathrm{pu} \& 1.044 \mathrm{pu}$ in A, B \& C Phase respectively without D-STATCOM as shown in figure 9. (a). In order to improve the load voltage to 1 pu balanced voltage in all three phases, D-STATCOM is connected, and a load voltage is observed to be of almost $1 \mathrm{pu}$ in all three phases as shown in figure 9. (b).

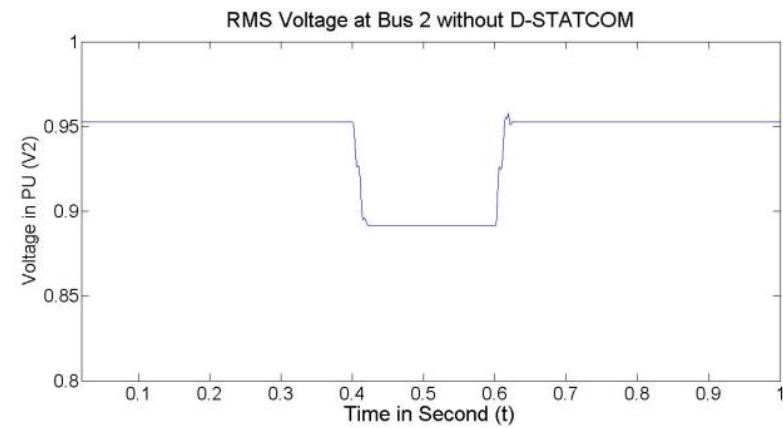

Figure 5.(a)

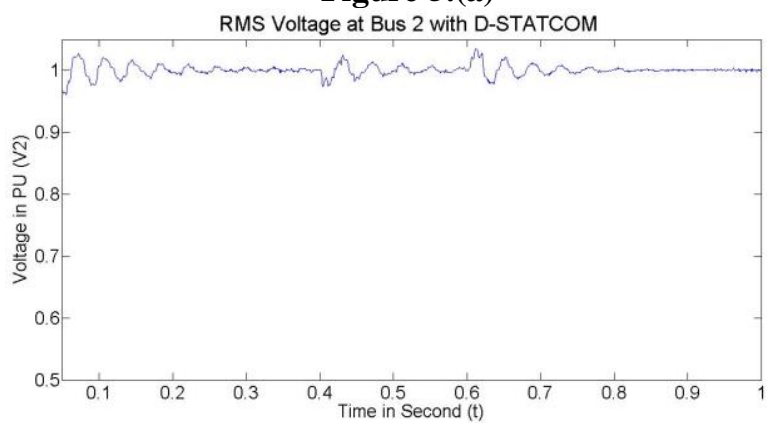

Figure 5. (b)

Figure 5. Simulation results of Voltage Sag due to heavy load at Bus2 (a) Without D-STATCOM (b) With DSTATCOM

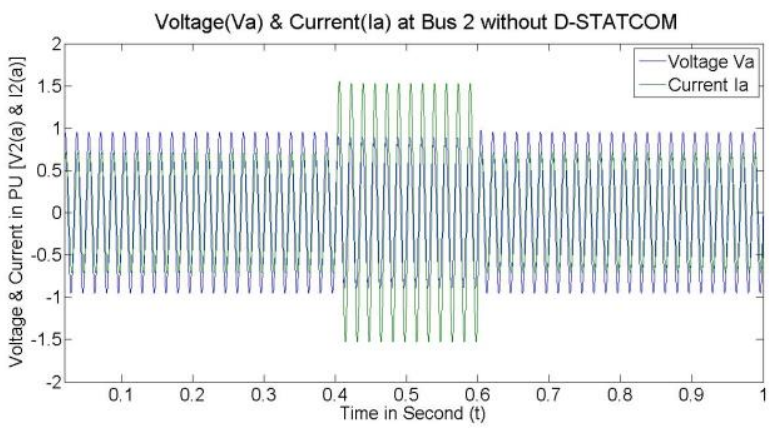

Figure 6. (a)

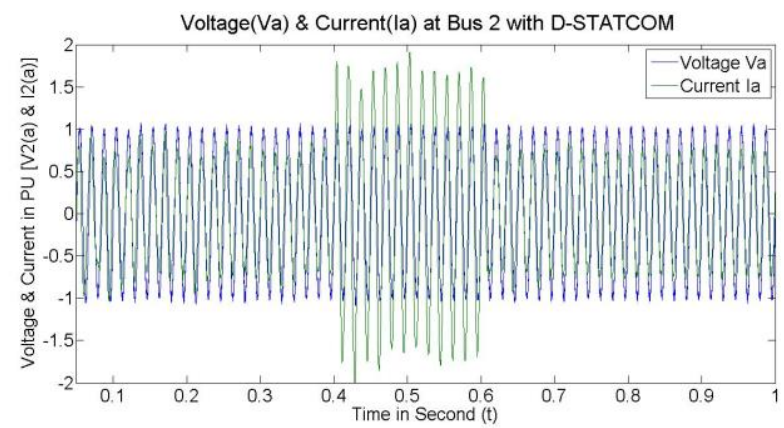

Figure 6. (b)

Figure 6. Simulation results of Voltage $\left(V_{a}\right) \&$ Current $\left(I_{a}\right)$ at Bus2 during heavy load (a) Without DSTATCOM (b) With D-STATCOM 


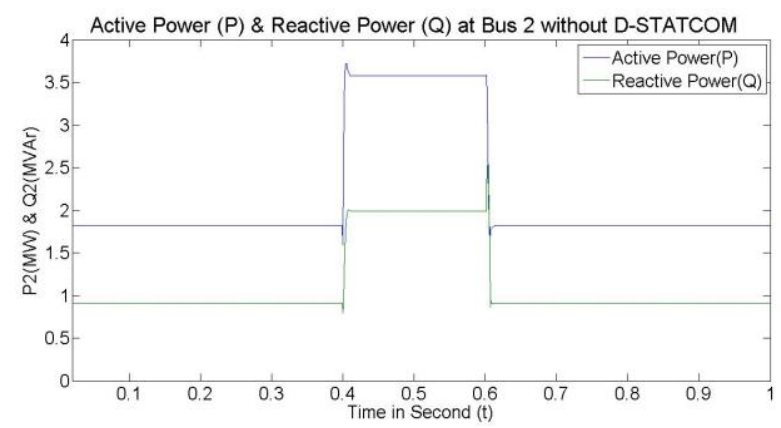

Figure 7. (a)

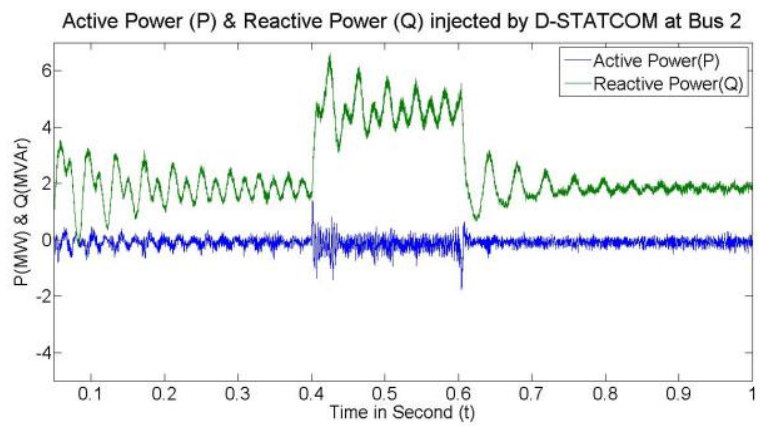

Figure 7. (b)

Figure 7. Simulation results of (a) Active (P) and Reactive (Q) power at Bus2 without D-STATCOM, (b) Active (P) and Reactive (Q) power injected by $\mathrm{D}$ STATCOM at Bus2 during heavy load.

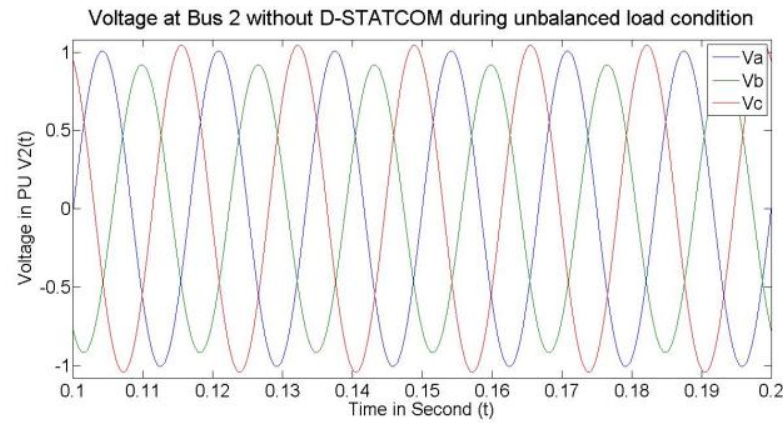

Figure 8. (a)

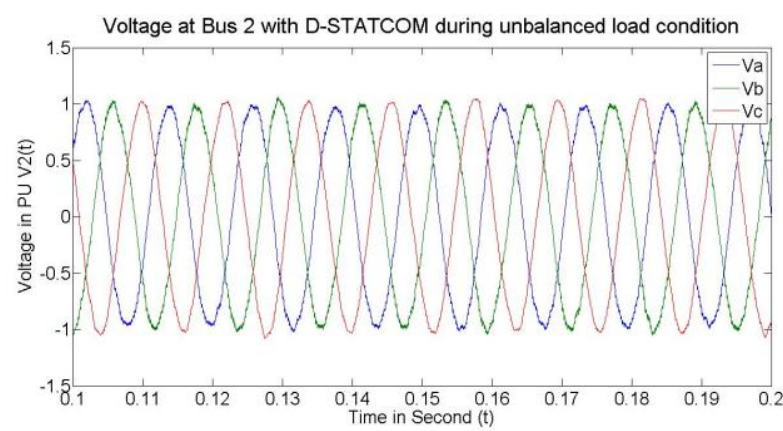

Figure 8. (b)

Figure 8. Simulation results of Voltage $\left(V_{a b c}\right)$ at Bus2 during Unbalanced load (a) Without D-STATCOM (b) With D-STATCOM

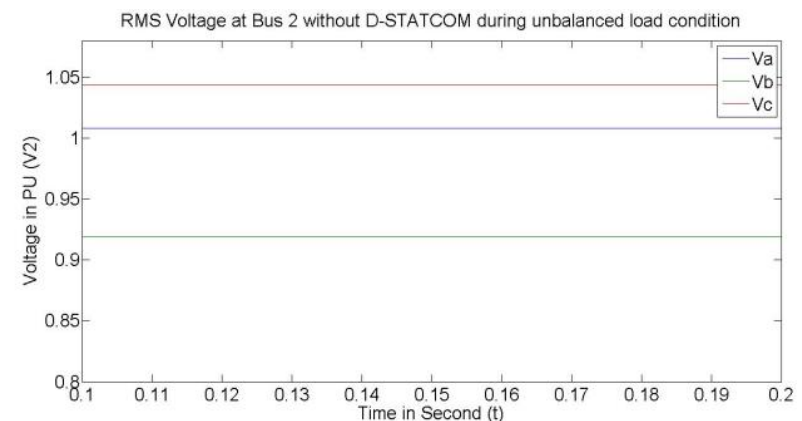

Figure 9. (a)

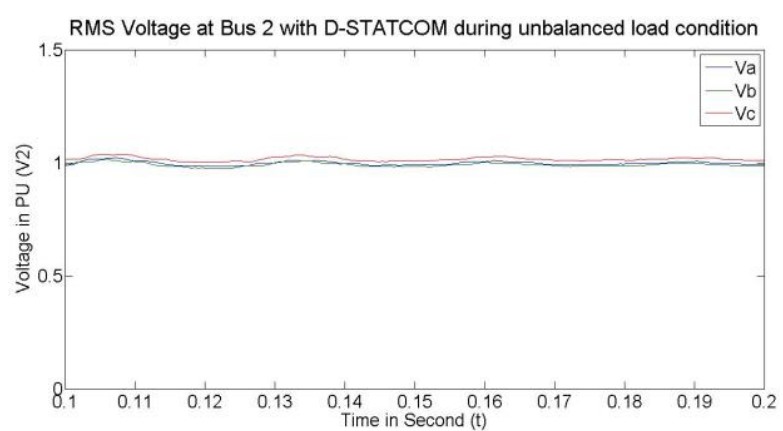

Figure 9. (b)

Figure 9. Simulation results of RMS Voltage at Bus2 during Unbalanced load (a) Without D-STATCOM (b)

With D-STATCOM

During 0.4 - 0.6 second, a double line (line B-line C with ground) to ground fault is taken place at the midway between the transmission line. Because of this unbalanced voltage sag will result changing the voltage at bus $\mathrm{B}_{2}$ to $0.9716 \mathrm{pu}$, 0.8979 and 0.9230 of Phase A, B and C respectively without D-STATCOM as shown in figure 10. (a). While correcting load voltage, during this fault condition with D-STATCOM connected, system tries to maintain the load voltage not absolutely $1 \mathrm{pu}$ in all the phases but fluctuating tightly around $1 \mathrm{pu}$ as shown in figure 10. (b).

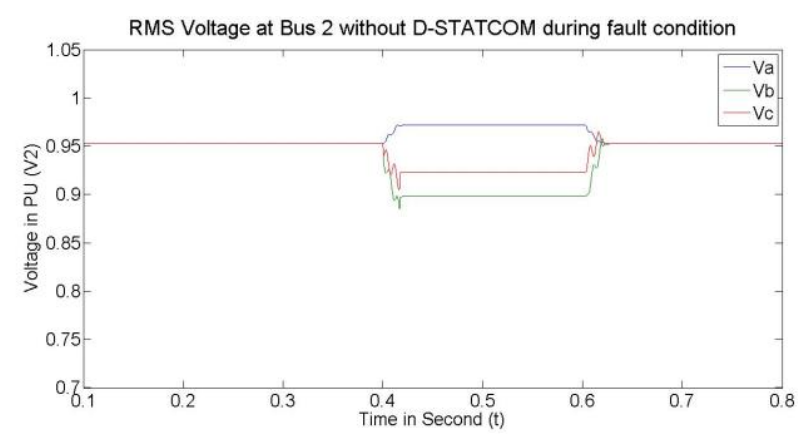

Figure 10. (a) 


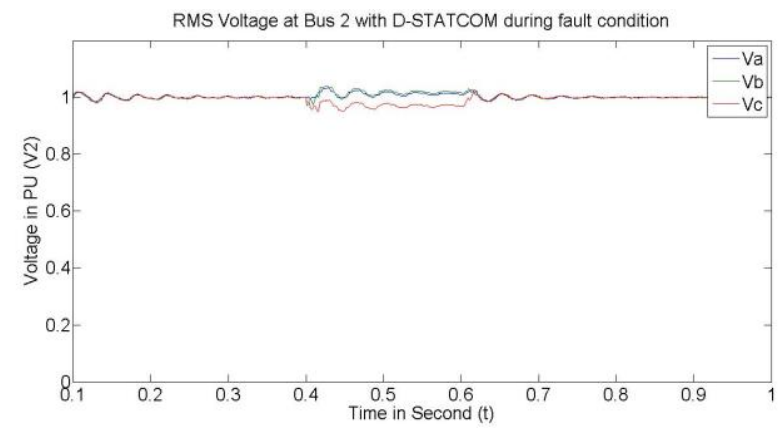

Figure 10. (b)

Figure 10. Simulation results of RMS Voltage at Bus2 during double line to ground (LLG) fault (a) Without DSTATCOM (b) With D-STATCOM

\section{Conclusions}

The paper presents the problems associated with voltage $\mathrm{sag} / \mathrm{swells}$ due to heavy balanced, unbalanced load \& fault condition, their mitigation techniques and role of $\mathrm{D}$ STACOM in addressing aforementioned power quality issues. Various phenomena are validated using PowerSystem block-sets available in MATLAB $^{\circledR} /$ SIMULINK $^{\circledR}$ platform. A PWM- based control scheme has been employed for the firing of power electronic switches of D-STATCOM. The comprehensive simulation results are observed including voltage and current at load point, active and reactive power supplied by D-STATCOM, RMS load voltage as well. From exhaustive analysis, it has been observed that with the DSTATCOM in operation the unbalance is fairly reduced and hence load voltage is restored to either its preset value or within narrow margin.

\section{References}

1. Rajiv K. Varma, Vinod Khadkikar, and Ravi Seethapathy, "Nighttime Application of PV Solar Farm as STATCOM to Regulate Grid Voltage", IEEE transactions on energy conversion, Volume. 24, NO. 4, December 2009, Page: 983.
2. Amit Singla, Sulata Bhandari, Er. Gagan Singh, "Comparative Performance Analysis Of PSCAD/EMTDC and MATLAB /SIMULINK Software for Modeling and Simulation Of DSTATCOM".

3. M. H. Haque, "Compensation of Distribution System Voltage Sag by DVR and DSTATCOM", Power Tech Proceedings, 2001 IEEE Proto, Volume 1, Sept 2001.

4. Sung-Min Woo, Dae-Wook kang and Woo-Chol Lee, "The Distribution STATCOM for Reducing the Effect of Voltage Sag \& Swell", IECON'01: The 27th Annual Conference of the IEEE Industrial Electronics Society, 2001.

5. N. G. Hingorani, L. Gyugi, "Understanding FACTS Concepts and Technology of Flexible AC Transmission system", IEEE press, 2000.

6. N. G. Hingorani, "Introducing Custom Power", IEEE Spectrum, Volume 32, Issue 6, June 1995, Pages: 41-48.

7. K. K. Sen, "STATCOM: Theory, Modeling, Application", in IEEE PES 1999 Winter Meeting proceedings, Pages: 1177-1183.

8. G. Sybille, Hoang Le-Huy, "Digital Simulation of Power Systems and Power Electronics using the MATLAB/Simulink Power System Blockset", in proceeding of IEEE PES'2000, Winter Meeting, Feb 2000, Pages: 2973-2982.

9. Pierre Giroux, G. Sybille, Hoang Le-Huy, "Modeling and Simulation of a Distribution STATCOM using Simulink's Power System Blockset", IECON'01: The 27th Annual Conference of the IEEE Industrial Electronics Society, 2001, Pages: 990-994.

10. M. S. Ei-Moursi, A. M. Sharaf, "Novel Reactive Power Controllers for the STATCOM and SSSC", Electrical Power System Research, Volume 76, Issue 1, August 2005, pages: 228-241.

11. Sidhartha Panda, Ramnarayan Patel, "Improving Power System Transient Stability With an Off- Centre Location of Shunt FACTs Devices", Journal of Electrical Engineering, Volume 57, No.6, 2006, Pages: 365-368.

12. S.V. Ravi Kumar, S. Siva Nagaraju, "Simulation of DSTATCOM \& DVR in Power Systems", ARPN Journal of Engineering \& Applied Sciences, Volume 2, No.3, June 2007, Pages: 7-13.

\section{Biographical notes}

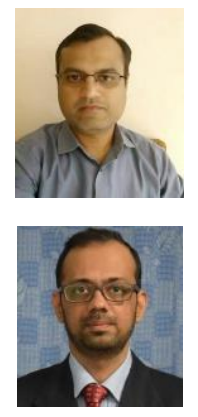

Naman B Bhatt has received the B.E. degree from C. K. Pithawala College of Engineering \& Techology, Surat, Gujarat, India in 2005 \& M.E. (Electrical) form Birla Vishvakarma Mahavidyalaya (Engineering College), Vallabh Vidyanagar, Gujarat, India in 2007. He is currently working as Assistant Professor in Electrical Engineering Department at Sarvajanik College of Engineering \& Technology, Surat (Gujarat), India. His research interest includes Power System Analysis, Power System Modeling \& Simulation, Power System Dynamics and Stability, Voltage Stability, FACTs Technology, Distributed Generation and Smart Grid Technology.

Shabbir S. Bohra has received the B.E. degree from Sardar Vallabhbhai Regional Engineering College, Surat (Gujarat), India in 1999, M.Tech. (Energy System Engineering) form Indian Institute of Technology, Bombay (Maharashtra), India in 2007 \& Ph.D. from Sardar Vallabhbhai National Institute of Technology, Surat, Gujarat, India in 2015. He is currently working as Professor in Electrical Engineering Department at Sarvajanik College of Engineering \& Technology, Surat (Gujarat), India. His research interest includes Power Electronics \& Drive, Renewable Energy System, Applications of Power Electronics to Power System, FACTS, Distributed Generation and Micro Grid Technology. 